\title{
Simulation Research on Participation Willingness of Industrial Company on Green Finance Policies based on Tripartite Game
}

\author{
Liping Wang ${ }^{1}$, Yuning $\mathbf{L i}^{2}$, Chuang $\mathrm{Li}^{3^{*}}$ \\ ${ }^{1 .}$ Finance and Economics College, Jimei University, Xiamen 361021, China \\ 2. School of Finance and Economics, Henan Polytechnic University, Jiaozuo 454000, China \\ ${ }^{3}$ School of Business Administration, Jimei University, Xiamen 361021, China \\ *Corresponding Author.
}

\begin{abstract}
The green finance policy is an important embodiment of the basic national policy of environmental protection in the financial system, and also an important guarantee for company to achieve green development. Based on the heterogeneous interest pursuit of the central state, local provinces and industrial companies, the article builds an evolutionary model of three game partners, analyzes the strategic choice of the stakeholders in the implementation process of the green finance policies, and simulates the dynamical track of evolution stability strategies of three partners. The results show that the management from the central state is very important to the implementation of the policy, and the supervision cost and punishment will also affect the final stability strategy; the policy incentive from the central state can effectively promote the enthusiasm of the local provinces to implement the green finance policies, but the implementation cost will seriously affect the willingness of the local government to help industrial companies; under the joint supervision effect of the central state, the local government's policy incentives and the complete market mechanism, industrial companies will enhance their willingness to participate in green finance policies.
\end{abstract}

Keywords: Green finance; willingness to participate; evolutionary game; numerical simulation; industrial company

\section{Introduction}

Under the background of promoting the ecological civilization and implementing the concept of green development, the green finance market and relevant policies in China are also constantly developing. In 2015, the State Council issued the overall plan for the reform of the ecological civilization system, which is the first time to propose the establishment of green finance system in China. In 2016, the People's Bank of China, cooperating with other seven state governments, issued the guidance on building up the green finance system, which formed a relatively complete policy framework and provided with the top-level design for development of green finance in China. In 2017, the People's Bank of China led and laid out a timetable and roadmap for the establishment of China's green finance system. Subsequently, the State Council decided to establish reform pilot in five provinces such as ZheJiang province, which marks the beginning of green finance practice in various regions of China. Driven by the policies of the central and local governments, the green finance market has been expanding in recent years in China. According to data released by the People's Bank of China, the green credit balance of Chinese banks reached more than 800 billion RMB by 2018, an increase of $11.2 \%$ over the previous year. Among them, more than 280 billion RMB of green bonds have been issued, with an inventory of nearly 600 billion RMB, at the forefront of the world. At the same time, many banks in China have been also increasing the development of green products, providing bond issuance and other support for the development of green projects, developing financial products themed green, and attracting social funds to support the development of green industries. Throughout the development process of China's green financial, it is not difficult to find that green finance policies have been mainly decided by the central state and then carried out by local governments. However, the local government has greater autonomy in the financial revenue, expenditure, investment field, and moreover pursues the maximization of regional interests, so there may be a big deviation between the central state's expectation in the target orientation ISSN: 0010-8189 
and action of green finance policies. In the process of policy implementation, conflicts of interests among local governments will also hinder the effective implementation of policies. In addition, conflicts of interest between the stakeholders seriously restricted the rapid development of China's green finance, especially the proportion of China's green finance credit in the total assets of commercial banks is still low, the market value of green industry is very small, some new financial tools such as the raise, financial leasing, asset securitization, the trust are seldom applied in the green financial sector. In this context, only to seek the interest balance of all partners and the evolution stability strategy, and continuously optimize the policy path, can better promote the development of green finance in China.

\section{Literature review}

Green finance is a market-based economic means of environmental protection, which is the intersection between green economy and finance, and a financial tool improving environmental quality and reducing environmental risks. From the perspective of the financial industry, green finance can effectively promote the development of the finance industry, the development of green finance is also an inevitable requirement for the sustainable development of finance industry, and enhance the sense of social responsibility of the finance industry. With the guidance of government's green policies and improvements of the public's awareness of green development, more and more consumers are pursuing green and environmental protection. In the background, company seeks new development opportunities through green finance, which is not only to meet market development needs but also the inevitable choice for sustainable development, so as to enhance their competitive advantages. At the same time, green development is the embodiment of corporate social responsibility, and in turn company with good social responsibility performance are more likely to win the trust of financial institutions, obtain more financing support, reduce financing costs, and improve the risk management ability of company. However, not all companies will actively participate in green finance activities. Song ${ }^{[1]}$ found that if the income gained by company cannot cover the costs of green production and environmental protection, they will have no incentive to comply with relevant policies. Therefore, the design of green finance policies considering the interests of company and the implementation of the incentive and compatible mechanism for the harmonious development of the government and company are crucial to the development of green finance. Wang ${ }^{[2]}$ pointed out that green finance should be built up based on the market mechanism and the formulation of relevant policies. Sheng ${ }^{[3]}$ found that if central government could sternly supervise, so the negative impact would be effectively alleviated because of interest conflicts among three partners on policy implementation.

In China, scholars mainly focused on the three research fields of green finance theory, green financial products and green financial policies. (1) Green finance theory. Domestic scholars generally believed that the green financial is different from traditional finance, and its core goal is to improve the environment and save resources through financial services. Green finance can not only promote scientific and technological innovation, optimize the industrial structure, also can guide social capital into the green industry, effectively reduce the financing cost of the green enterprise, promote the sustainable development of economy and the financial sector. However, there are still some difficulties in the development of green finance in China. The green finance system is not yet perfect, the innovation of green financial products is insufficient, and there is no guarantee in the legal system ${ }^{[4]}$. Based on the theoretical connotation of the development of green finance in China, some researchers draw lessons from the practical experiences of green finance in developed countries, focus on the prominent problems restricting the development of green finance to explore the realization path of green finance that is suitable for China's national conditions from multiple levels and angles ${ }^{[5]}$. (2) Green financial products. Green financial products are the main forms of green finance, such as green credit, green insurance, green securities, green funds, carbon finance and so on. The research on green financial products mainly focuses on green credit. In the current economic environment, the green credit policy plays a positive role in promoting the development of green finance, which can reduce the debt financing cost of green company and improve the level of information disclosure. A certain intensity of green credit as an incentive policy can bring economic and environmental win-win results. At the same time, the sustainable development of green finance is also inseparable from financial supervision. He et al. ${ }^{[6]}$ pointed out that the government should build and improve the green financial system through policies and regulations. On the

ISSN: 0010-8189 
whole, China's green financial products are still relatively limited, especially the green insurance and green fund are relatively single and small in scale, the market regulation mechanism is not mature, and the government and relevant departments also lacks certain guidance experience. In terms of green securities, China is gradually changing from government-led to market-led, but there are still some deficiencies in government supervision, information disclosure and incentive and restraint mechanism. It is noteworthy that China's carbon finance market has been developing rapidly in recent years. Scholars' research mainly focuses on the trading mechanism of the carbon finance market, the impact of carbon finance on the economy and the pricing mechanism, so as to find a carbon finance development path suitable for China's national conditions. (3) Green financial policies. Zhang ${ }^{\text {[7] }}$ analyzed the practices of green credit policy in China from the perspective of top-down and bottom-up reform, and found that China's policy were not completely implemented. Liu ${ }^{[8]}$ used CGE model to evaluate China's green finance policy, and pointed out that the current green finance policy system should strengthen fiscal policy and financial market infrastructure construction.

Through literature review can be found that the existing research for the green financial development could provide very valuable ideas and suggestions, but there are mainly problems at the macro level not in specific implementation process for green finance policy, especially the game relationships of multiple stakeholders are few discussed. As a result, some suggestions are impossible to play a substantial role in practice. Therefore, this paper adopts the dynamic game method to construct the three-partners evolutionary game model including the central state, local government and companies, studies the evolution stability strategies of these three stakeholders, and further numerically simulates the driving factors of green finance policy in the implementation process, so as to provide decision-making reference for the development and path optimization of green finance in China.

\section{Construction and analysis of evolutionary game model}

\subsection{Model hypothesis}

Based on the above analysis, it is concluded that it is necessary for green finance policy that the central state should cooperate with local governments and company in the implementation. Therefore, this paper constructs a game model of green finance policy including these three stakeholders. In detailed, the main responsibility of central government is to formulate relevant policies and supervise the implementation effect of local governments, local governments are responsible for the implementation of green finance policies, and enterprise obtains some development support through the green finance policy at the certain cost.

Firstly, the central state's strategy choices, cost and benefit are analyzed as following. In order to ensure the smooth implementation of green finance policies, the central state should supervise the implementation effect of green finance policies of local governments. Without regulation, local governments may skimp on or do nothing about policy. Therefore, it should be assumed that the central state has two strategic choices of supervision and non-supervision (supervision and non-supervision), which is denoted as $A_{1}=\left\{a_{1,1}, a_{1,2}\right\}$. The probability of central government supervision is set as $x$, and the probability of non-supervision is set as $1-x$. Of course, central government has to take the burden of regulation cost, which is denoted as $b$. The interests of the central state are mainly reflected in the increase of fiscal revenue and good social image, but this depends on the response strategies of company. If companies respond negatively to green finance policies, the central state could not get good social benefits, which is set as v0. If the central state supervises the local government, the local government would conscientiously carry out the green finance policies and then promote company to positively respond to relevant policies, then the central state would have very good social benefits set as $v_{1}$. If the central state does not supervise, but the company may respond to the policy actively because of the need of green development, then the social benefits of the central state are set as $v_{2}$.

Secondly, the strategy choices, cost and benefit of local government are showed as following. Only when the green finance policy formulated by the central government is translated into specific actions of local governments, can

ISSN: 0010-8189 
the development of green finance be promoted. The strategic choices of the local government are to give policy incentives to company or not, denoted as $A_{2}=\left\{a_{2,1}, a_{2,2}\right\}$. The incentives probability of local government is equal to $y$, and the probability of no incentives is equal to $1-y$. If local governments are found by the central government to do anything, they would face a bad financial penalty $d$. If the local government actively implements the central policies, they would get the financial reward $s_{1}$. At this point, the implementation cost of the local government is equal to $m$. Local governments mainly reduce the green development cost of company through financial subsidies or tax breaks to encourage the smooth implementation of green finance policies, and the local government provide fiscal subsidy $s_{2}$ to company. If the company negatively treats the green finance policy, the local government will pay amount of environmental damage equal to $w_{0}$ due to the dirty development of enterprise. When companies actively participate in green development, the environmental benefits gained by local governments are equal to $w_{1}$.

Finally, the enterprise's strategy choices, cost and benefit are explained as following. In order to obtain the preferential treatment and support of the government's green finance policies, company need to make a positive response such as green production and innovation of green products. The strategy choices of the enterprise are positive or negative response to the green finance policy, denoted as $A_{3}=\left\{a_{3,1}, a_{3,2}\right\}$. The positive response probability of firm is equal to $z$, and negative response is equal to $1-z$. The interests of company are mainly manifested in the increase of operating revenue and profit. Assuming that the enterprise negatively responds to green finance policy, its future revenue is equal to $e_{0}$. At the same time, when companies do negative response, they need to spend some cost $c_{0}$ in controlling the pollution. When the enterprise positively responds to the policy, the future operating income can be equal to $e_{1}$, meanwhile the enterprise would pay a certain cost, equal to $c_{1}$, for carrying out green production, scientific research, technological innovation and equipment transformation.

Table 1 All the variables and its meanings

\begin{tabular}{|c|c|}
\hline Variable & Variable meaning \\
\hline$v_{0}$ & the gains of central state, when enterprises adopt 'negative response' strategy \\
\hline$v_{1}$ & $\begin{array}{l}\text { the gains of central state, when enterprises adopt 'negative response' strategy and the } \\
\text { central government adopt 'supervision' strategy }\end{array}$ \\
\hline$v_{2}$ & $\begin{array}{l}\text { the gains of central state, when enterprises adopt a 'positive response' strategy and the } \\
\text { central state adopt 'non-supervision' strategy }\end{array}$ \\
\hline$b$ & the regulation cost of central state \\
\hline$m$ & the implementation cost of local governments for green finance policies \\
\hline$w_{0}$ & $\begin{array}{c}\text { environmental damage of local provinces, when industrial companies adopt 'negative } \\
\text { response' strategies }\end{array}$ \\
\hline$w_{1}$ & $\begin{array}{c}\text { environmental benefits of local provinces, when industrial companies adopt 'positive } \\
\text { response' strategy }\end{array}$ \\
\hline$S_{1}$ & $\begin{array}{c}\text { central subsidies provided by the central government to local governments, under the } \\
\text { supervision of the central state and active action of local provinces }\end{array}$ \\
\hline$S_{2}$ & $\begin{array}{l}\text { financial subsidies provided by local provinces to enterprises which actively respond to } \\
\text { policies }\end{array}$ \\
\hline$d$ & $\begin{array}{l}\text { the financial penalty for the local provinces' inaction because of the management of } \\
\text { the central state }\end{array}$ \\
\hline$e_{0}$ & future operating income, when the enterprise negatively responds \\
\hline$e_{1}$ & future operating income, when the industrial companies positively responds \\
\hline$c_{0}$ & $\begin{array}{c}\text { the cost of pollution reduce paid by industrial company when it adopts 'negative } \\
\text { response' strategy }\end{array}$ \\
\hline
\end{tabular}


$c_{1}$ the cost of green innovation, when an company adopts 'positive response' strategy

$x \quad$ the probability of the central state manage the local provinces

$y \quad$ the probability of the local provinces adopts 'policy incentives' strategy

$z$ the probability of the enterprise responding positively to the policy

According to the above assumptions and the game relationships among the three parties, the income payment matrix of the central state, local governments and enterprises can be obtained, as shown in table 2 below.

Table 2 Return of different strategies

\begin{tabular}{ccc}
\hline Number & Strategy combination & Utility \\
\hline 1 & $\left(a_{1,1}, a_{2,1}, a_{3,1}\right)$ & $\left(v_{1}-b-s_{1}, w_{1}-s_{2}+s_{1}-m, e_{1}-c_{1}+s_{2}\right)$ \\
2 & $\left(a_{1,1}, a_{2,1}, a_{3,2}\right)$ & $\left(-v_{0}-b-s_{1},-w_{0}+s_{1}-m, e_{0}-c_{0}\right)$ \\
3 & $\left(a_{1,1}, a_{2,2}, a_{3,1}\right)$ & $\left(v_{1}-b+d, w_{1}-d, e_{1}-c_{1}\right)$ \\
4 & $\left(a_{1,1}, a_{2,2}, a_{3,2}\right)$ & $\left(-v_{0}-b+d,-w_{0}-d, e_{0}-c_{0}\right)$ \\
5 & $\left(a_{1,2}, a_{2,1}, a_{3,1}\right)$ & $\left(v_{2}, w_{1}-s_{2}-m, e_{1}-c_{1}+s_{2}\right)$ \\
6 & $\left(a_{1,2}, a_{2,1}, a_{3,2}\right)$ & $\left(-v_{0},-w_{0}-m, e_{0}-c_{0}\right)$ \\
7 & $\left(a_{1,2}, a_{2,2}, a_{3,1}\right)$ & $\left(v_{2}, w_{1}, e_{1}-c_{1}\right)$ \\
8 & $\left(a_{1,2}, a_{2,2}, a_{3,2}\right)$ & $\left(-v_{0},-w_{0}, e_{0}-c_{0}\right)$ \\
\hline
\end{tabular}

In the model of evolutionary game, all game players are bounded rational decision makers. Therefore, the central state, local provinces and companies cannot immediately find their own optimal strategies in the initial stage. Instead, they keep trying and learning in the game to find the optimal strategies. In the following part, the replication dynamic equations of central state, local government and industrial companies are constructed to analyze the evolutionary stability strategies of the three parties.

\subsection{Benefit function of participants}

(1) Expected return of the central state

When the central state makes up policy supervision over local governments, their expected return is assumed $U_{11}$, and the expected return without supervision is $U_{12}$, then the average expected return is equal to $\bar{U}_{1}$. The expected returns can be set as follows:

$$
\left\{\begin{aligned}
U_{11}= & y z\left(v_{1}-b-s_{1}\right)+y(1-z)\left(-v_{0}-b-s_{1}\right)+(1-y) z\left(v_{1}-b+d\right) \\
& +(1-y)(1-z)\left(-v_{0}-b+d\right) \\
U_{12}= & y z v_{2}-y(1-z) v_{0}+(1-y) z v_{2}-(1-y)(1-z) v_{0} \\
\overline{U_{1}}= & x U_{11}+2(1-x) U_{12}
\end{aligned}\right.
$$

(2) Expected return of local governments

The expected return of local government is assumed $U_{21}$ when local government adopts 'incentive' strategy, and the expected return without policy incentive strategy is $U_{22}$, and the average expected benefit of local government is equal to $\bar{U}_{2}$.The expected returns can be set as follows: 


$$
\left\{\begin{aligned}
U_{21}= & x z\left(w_{1}-s_{2}+s_{1}-m\right)+x(1-z)\left(-w_{0}+s_{1}-m\right)+(1-x) z\left(w_{1}-s_{2}-m\right) \\
& \quad(1-x)(1-z)\left(-w_{0}-m\right) \\
U_{22}= & x z\left(w_{1}-d\right)+x(1-z)\left(-w_{0}-d\right)+(1-x) z w_{1}-(1-x)(1-z) w_{0} \\
\overline{U_{2}}= & y U_{21}+(1-y) U_{22}
\end{aligned}\right.
$$

(3) Expected return of the enterprise

When enterprise chooses a positive response strategy, its expected return is $U_{31}$, and When enterprise chooses a negative response strategy, its expected return is $U_{32}$, and then the average expected return of an enterprise is equal to $\bar{U}_{3}$. They can be set as follows:

$$
\left\{\begin{aligned}
U_{31}= & x y\left(e_{1}-c_{1}+s_{2}\right)+x(1-y)\left(e_{1}-c_{1}\right)+(1-x) y\left(e_{1}-c_{1}+s_{2}\right) \\
& \quad+(1-x)(1-y)\left(e_{1}-c_{1}\right) \\
U_{32}= & x y\left(e_{0}-c_{0}\right)+x(1-y)\left(e_{0}-c_{0}\right)+(1-x) y\left(e_{0}-c_{0}\right)+(1-x)(1-y)\left(e_{0}-c_{0}\right) \\
\overline{U_{3}}= & z U_{31}+(1-z) U_{32}
\end{aligned}\right.
$$

\subsection{Construction of replication dynamic equation}

Based on formulas (1), (2) and (3), the replication dynamic equation of the three parties is constructed as follows:

$$
\begin{aligned}
& F(x)=\frac{d x}{d t}=x\left(U_{11}-\bar{U}_{1}\right)=x(1-x)\left[\mathrm{d}-b-\left(d+\mathrm{s}_{1}\right) y+\left(v_{1}-v_{2}\right) z\right] \\
& F(y)=\frac{d y}{d t}=y\left(U_{21}-\bar{U}_{2}\right)=y(1-y)\left(s_{1} x+d x-s_{2} z-\mathrm{m}\right) \\
& F(\mathrm{z})=\frac{d z}{d t}=z\left(U_{31}-\bar{U}_{3}\right)=z(1-z)\left[s_{2} y+\left(\mathrm{e}_{1}-c_{1}-e_{0}+c_{0}\right)\right]
\end{aligned}
$$

Formulae (4), (5) and (6) respectively represent the replication dynamic equation of central government, local government and enterprise. Each game subject will dynamically choose the best corresponding strategy according to cost and gain in every game. Therefore, this paper analyzes the maximum gain of stakeholders though the evolutionary stable strategy (ESS).

\subsection{Equilibrium point and stability analysis of evolutionary game}

Respectively assuming $F(x)=0, F(y)=0, F(z)=0$, so it will get eight equilibrium of the evolution games, which are $E_{1}(0,0,0), E_{2}(1,0,0), E_{3}(0,1,0), E_{4}(0,0,1), E_{5}(1,1,0), E_{6}(1,0,1), E_{7}(0,1,1)$, $E_{8}(1,1,1)$. In evolutionary game, the stability of equilibrium point should be analyzed before equilibrium point can be defined the ultimate ESS. In the dynamic replication system of multi-partner game, the strategy combination is gradually stable only if a strictly Nash equilibrium and pure strategy Nash equilibrium exist. Therefore, the paper only need to analyze these eight gradually stability points. The gradually stability of the equilibrium points can be got by evaluating the eigenvalues of the Jacobian matrix. By respectively taking the partial derivatives of $F(x)$ on $x, F(y)$ on $y, F(z)$ on $z$, and the Jacobian matrix of three-partner evolutionary game could be obtained as follows: 


$$
\begin{gathered}
J=\left[\begin{array}{ccc}
\frac{\partial F(y)}{\partial x} & \frac{\partial F(x)}{\partial y} & \frac{\partial F(x)}{\partial z} \\
\frac{\partial F(y)}{\partial y} & \frac{\partial F(y)}{\partial z} \\
\frac{\partial F(z)}{\partial x} & \frac{\partial F(z)}{\partial y} & \frac{\partial F(z)}{\partial z}
\end{array}\right]= \\
x(1-x)\left(-s_{1}-d\right) \\
\left.\begin{array}{ccc}
(1-2 x)\left[d-b-\left(d+\mathrm{s}_{1}\right) y+\left(v_{1}-v_{2}\right) z\right] & (1-x)\left(v_{1}-v_{2}\right) \\
y(1-y) & -y(1-y) s_{2} \\
0 & (1-2 y)\left(s_{1} x+d x-s_{2} z-\mathrm{m}\right) & (1-2 z)\left[s_{2} y+\left(e_{1}-c_{1}-e_{0}+c_{0}\right)\right]
\end{array}\right]
\end{gathered}
$$

Put the equilibrium points into the Jacobian matrix and obtain the eigenvalues:

(1) The Jacobian matrix at the equilibrium point $E_{1}(0,0,0)$ :

$$
J_{1}=\left[\begin{array}{ccc}
\mathrm{d}-b & & \\
& -m & \\
& & e_{1}-c_{1}-e_{0}+c_{0}
\end{array}\right]
$$

The eigenvalue of the matrix can be obtained as:

$$
\lambda_{1}=d-b, \lambda_{2}=-m, \lambda_{3}=e_{1}-c_{1}-e_{0}+c_{0}
$$

(2) The Jacobian matrix at the equilibrium point $E_{2}(1,0,0)$ :

$$
J_{2}=\left[\begin{array}{lll}
\mathrm{b}-d & & \\
& s_{1}+d-\mathrm{m} & \\
& & e_{1}-c_{1}-e_{0}+c_{0}
\end{array}\right]
$$

The eigenvalue of the matrix can be obtained as:

$$
\lambda_{1}=b-d, \lambda_{2}=s_{1}+d-m, \lambda_{3}=e_{1}-c_{1}-e_{0}+c_{0}
$$

(3) The Jacobian matrix at the equilibrium point $E_{4}(0,0,1)$ :

$$
J_{4}=\left[\begin{array}{lll}
(\mathrm{d}-b)+\left(v_{1}-v_{2}\right) & & \\
& -\mathrm{s}_{2}-m & \\
& & -e_{1}+c_{1}+e_{0}-c_{0}
\end{array}\right]
$$

The eigenvalue of the matrix can be obtained as:

$\lambda_{1}=(d-b)+\left(v_{1}-v_{2}\right), \lambda_{2}=-s_{2}-m, \lambda_{3}=-e_{1}+c_{1}+e_{0}-c_{0}$

(4) The Jacobian matrix at the equilibrium point $E_{6}(1,0,1)$ :

$$
J_{6}=\left[\begin{array}{ccc}
-\left[(\mathrm{d}-b)+\left(v_{1}-v_{2}\right)\right] & & \\
& s_{1}+d-s_{2}-\mathrm{m} & \\
& & -e_{1}+c_{1}+e_{0}-c_{0}
\end{array}\right]
$$

The eigenvalue of the matrix can be obtained as:

$$
\lambda_{1}=-(d-b)-\left(v_{1}-v_{2}\right), \lambda_{2}=s_{1}+d-s_{2}-m, \lambda_{3}=-e_{1}+c_{1}+e_{0}-c_{0}
$$

(5) The Jacobian matrix at the equilibrium point $E_{8}(1,1,1)$ : 


$$
J_{8}=\left[\begin{array}{lll}
\mathrm{b}+\mathrm{s}_{1}+\left(v_{2}-v_{1}\right) & & \\
& \mathrm{s}_{2}+\mathrm{m}-\mathrm{s}_{1}-d & \\
& & -\mathrm{s}_{2}-\left(e_{1}-c_{1}-e_{0}+c_{0}\right)
\end{array}\right]
$$

The eigenvalue of the matrix can be obtained as:

$$
\lambda_{1}=b+s_{1}+\left(v_{2}-v_{1}\right), \lambda_{2}=s_{2}+m-s_{1}-d, \lambda_{3}=-s_{2}-\left(e_{1}-c_{1}-e_{0}+c_{0}\right)
$$

According to the kinetic theory, when the eigenvalues of the Jacobian matrix corresponding to an equilibrium point are all negative, this point is a locally gradually stable point. If there is at least one positive value, it is an unstable point. Thus $E_{3}(0,1,0), E_{5}(1,1,0)$ and $E_{7}(0,1,1)$ are all not gradually stable points after all they have at least one positive eigenvalue.

\section{Simulation analysis}

\subsection{Simulation of evolution game strategy}

According to the above theory and model analysis, the central state, local provinces and companies all play a very important role in the successful implementation of green finance policy, and the implementation effect of policy would be changed with the change of relevant parameters. Therefore, this paper further uses MATLAB software to quantifiably simulate and analyze the evolution trajectory of three stakeholders in the decision-making process of green finance policy.

\section{(1)Scenario 1}

The central government's regulatory costs are greater than the fines paid by local governments $(b>d)$. When companies respond positively to the policy, the social benefits of the central state with regulation are greater than no regulation $\left(v_{1}>v_{2}\right)$. The sum of the local government's policy implementation costs and subsidies to industrial companies is greater than the central state's subsidies to local governments $\left(m+s_{2}>s_{1}\right)$. The difference between the benefits and costs of industrial companies positive response to green finance policy is smaller than that of negative response $\left(e_{1}-c_{1}<e_{0}-c_{0}\right)$. In this case, the central state will not choose to regulate the strategy, local governments will not choose to carry out policy incentives, and industrial company would choose the negative response strategy. In this case, $E_{1}(0,0,0)$ is the unique ESS. Thus, we supposed $d=3, b=5, m=3$, $s_{1}=2, s_{2}=3, v_{1}=2, v_{2}=1, c_{0}=2, c_{1}=3, e_{0}=5, e_{1}=4$. Under the above constraints, the paper analyzes the robustness of ESS though numerical simulation method, and shows the result in fig.1.

From fig.1, it can be seen that the probability of central government with supervision, local government with positive action and industrial enterprises with positive response, that is $x, y, z$, will continue to decrease until converges to 0 , no matter what the initial value is. At this time, the convergence rate of local governments without policy incentives is the fastest, and the lower the initial probability of the central state and industrial companies, the faster the speed of non- supervision and passive participation will be. This shows that when the central state's supervision cost is large, it will affect the supervision probability of the central state, especially when the central state's management causes a large cost burden, the central state would even have no management. Furthermore, without the supervision, for their own interests, local governments will not seriously implement policies, or even ignore the capital needs of green development, that is, they will not provide industrial companies with any fiscal subsidies and other incentive measures. Consequently, without the support of local governments, the green motivation of enterprises developing $R \& D$ and green production innovation will be seriously insufficient. Eventually, green finance policies will have to stay in form rather than in practice. 

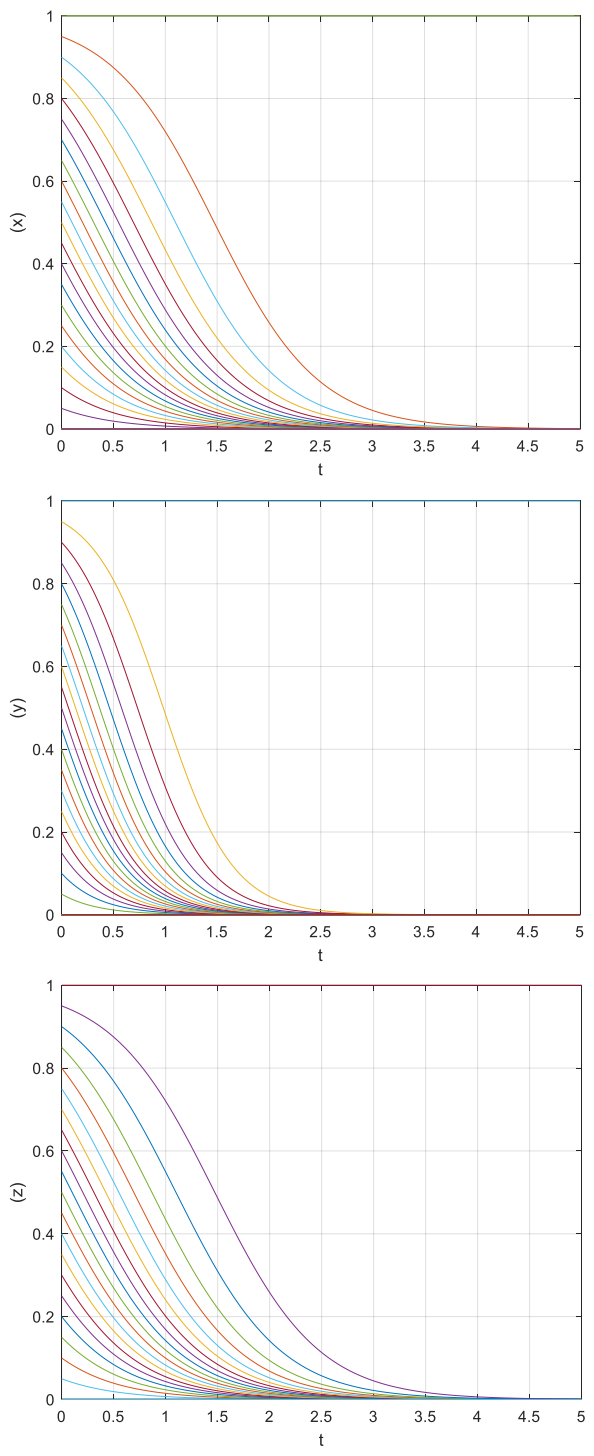

Fig. 1 The evolution towards $E_{1}(0,0,0)$
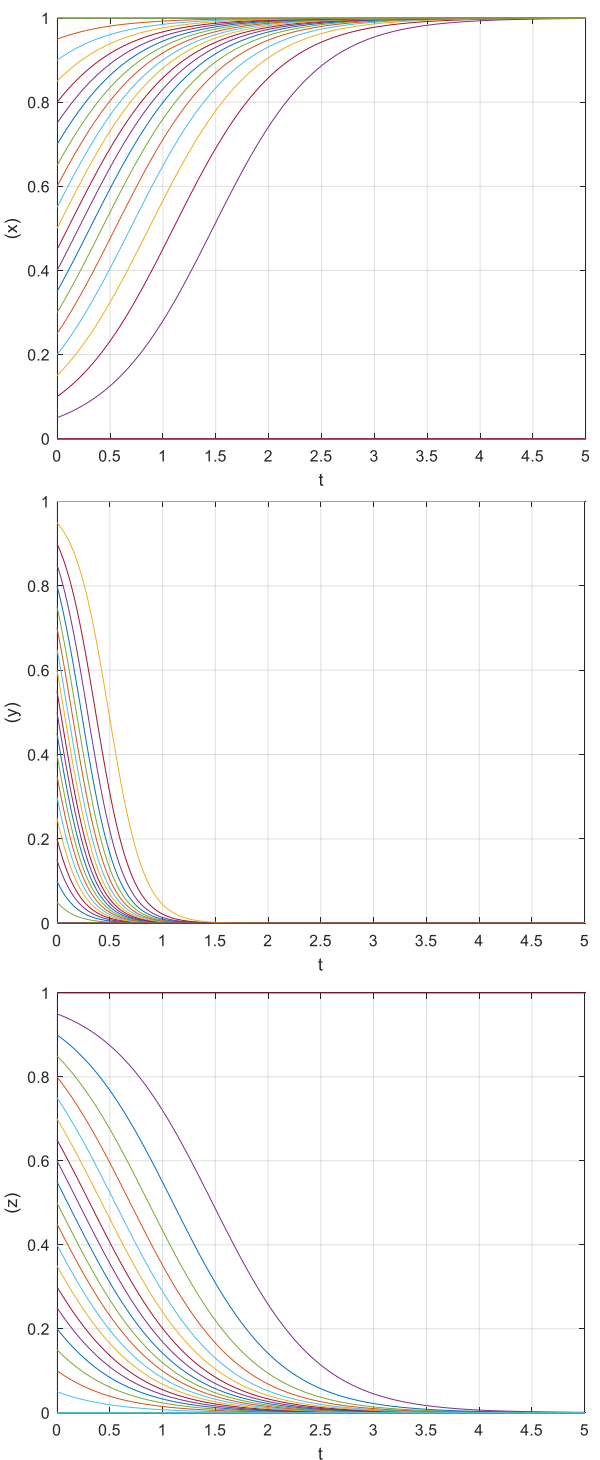

Fig.2 The evolution towards $E_{2}(1,0,0)$

\section{(2)Scenario 2}

The central government's regulatory costs are smaller than the fines paid by local governments $(b<d)$, when enterprises respond positively to the policy, the social benefits of the central government with regulation are greater than no regulation $\left(v_{1}>v_{2}\right)$. Under the background of supervision, the sum of the subsidies supplied by the central state and the fines paid by local provinces without policy incentives is less than the implementing cost of green finance policies $\left(\mathrm{s}_{1}+d<m\right)$. The difference between the benefits and costs of enterprises' positive response to green finance policies is smaller than that of negative response $\left(e_{1}-c_{1}<e_{0}-c_{0}\right)$. In this case, the central state will choose the supervision strategy, local provinces will not choose policy incentives strategy, and enterprises will choose the negative response strategy. In the state, $E_{2}(1,0,0)$ is the unique ESS. Thus, the paper supposed $d=4, b=2, m=6, s_{1}=1, s_{2}=3, v_{1}=2, v_{2}=1, c_{0}=2, c_{1}=3, e_{0}=5, e_{1}=4$. When the above constraints are met, the simulation result are illustrated in fig.2.

As could be explained from the figure, the probability, that is $x, y, z$, will eventually converge to $E_{2}(1,0,0)$ 
regardless of the initial value. The higher the initial regulatory willingness of the central state, the faster it tends to regulate, because it can bring positive benefits. The time what the local government's strategy selection converges to zero is the shortest, because the cost of local state's implementation is too much, even more than the fine, so as to maximize their own benefis, even if the central state strictly supervises, the local state will not take policy incentives measures. In the market, if enterprise cannot get net gains only from its own green innovation, it will choose a negative response strategy if it cannot get corresponding support in the long run even though its initial intention is very strong. The central state has an incentive to regulate local governments only if the benefits outweigh the costs of its own regulation. When all the cost including labor, material and financial measures used by local governments to implement green financial policies are higher than the sum of fines and subsidies from the central state, local governments will be inclined to give up policy incentives, and the smaller the initial probability is, the faster the rate of giving up policy incentives will be. If it is very difficult for enterprises to get preferential treatment on green finance from local governments, they will not carry out green innovation and production.

\section{(3)Scenario 3}

When the difference between supervision and cost of the central state is greater than the difference between the social benefits of the central state with supervision or non-supervision $\left(b-d>v_{1}-v_{2}\right)$, the sum of local government policy implementation costs and subsidies to enterprises is greater than $0\left(s_{2}+m>0\right)$, the difference between the benefits and costs of enterprises' positive response to green finance policies is greater than that of negative response $\left(e_{1}-c_{1}>e_{0}-c_{0}\right)$, the central government will not choose non-supervision strategy, local governments will choose not to provide policy incentives, but enterprises will respond to the policy actively, that is to say, $E_{4}(0,0,1)$ is the unique ESS. Thus, we supposed $d=3, b=5, m=3, s_{1}=2, s_{2}=3, v_{1}=3$, $v_{2}=2, c_{0}=2, c_{1}=3, e_{0}=4, e_{1}=6$. Numerical simulation results satisfying the above constraints are shown in fig. 3 .

It can be deduced from the figure, the probability $x, y,{ }^{2}$ will converge to $E_{4}(0,0,1)$ no matter what the initial value is. The lower the initial willingness of the central government and local governments, the faster the convergence to 0. Local governments, without central supervision and support, are the fastest to opt out of incentives. In the market, enterprises can gain certain benefits only by their own innovation. Even if their initial intention is low, they will choose to respond positively in the end, because in the long run, enterprises can gain positive benefits. Therefore, when the central state should pay more attentions to regulatory costs than its returns, the central state will give up regulate in order to maximize its own interests. Without central state oversight, local states tend not to provide policy incentives. For industrial companies, if the policy response, the gains from green innovation and production is more than the previous earnings, in the case of long term can benefit even without the support of local government, the enterprise also has a lot of willingness to participate in the green finance policies, but it takes a longer time. In short, the support from local government can better promote the green innovation of the enterprise.

\section{(4)Scenario 4}

When the difference between the supervision cost and benefits of central government is smaller than the difference between the social benefits of the central state with supervision or non-regulation $\left(b-d<v_{1}-v_{2}\right)$, under the supervision of the central state, the sum of the subsidies from the central state and the fines is less than the sum of the costs of implementing green finance policies and the financial subsidies to enterprises $\left(s_{1}+d<s_{2}+m\right)$, the difference between the benefits and costs of enterprises with positive response strategy is greater than that of negative response $\left(e_{1}-c_{1}>e_{0}-c_{0}\right)$, the central state would take the regulatory action, the local provinces would not provide policy incentives, and the industrial companies would respond positively to the policy. In this case, $E_{6}(1,0,1)$ is the unique ESS. Thus, we supposed $d=2, b=3, m=4, s_{1}=4, s_{2}=3, v_{1}=5, v_{2}=3$, 
$c_{0}=2, c_{1}=3, e_{0}=4, e_{1}=6$.

Numerical simulation results satisfying the above constraints are shown in

fig.4.
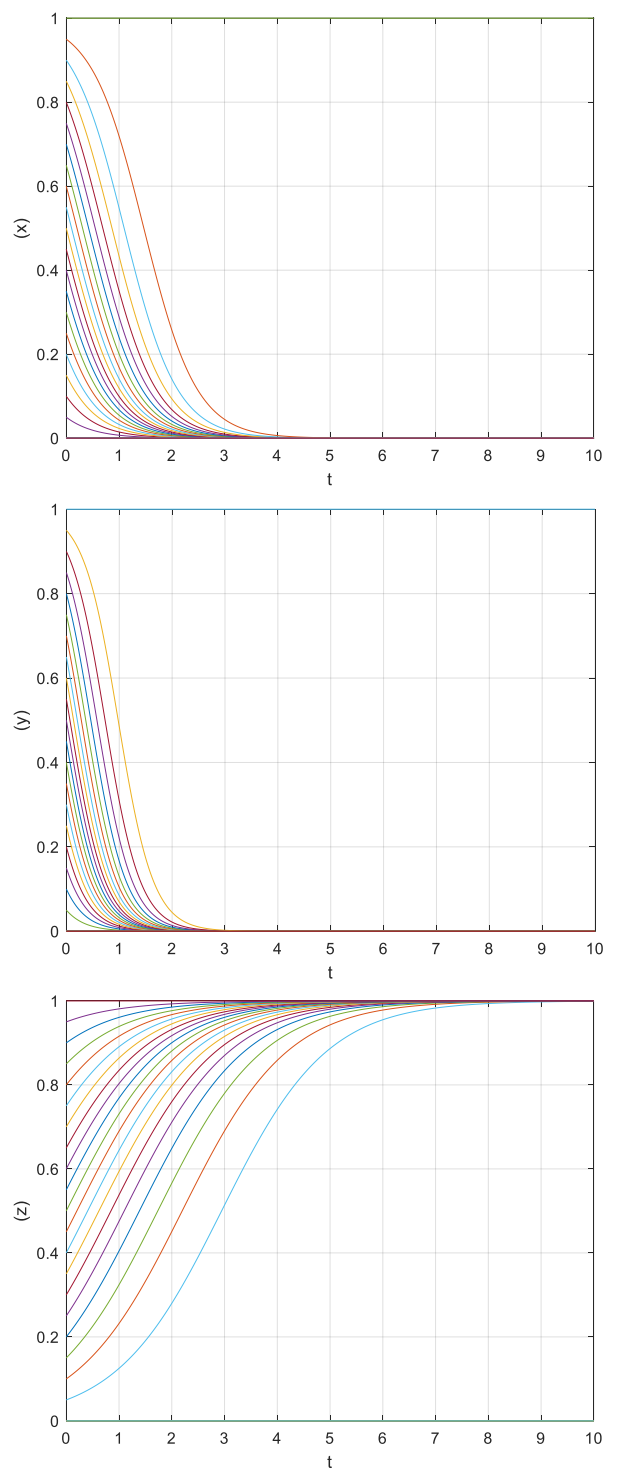

Fig.3 The evolution towards $E_{4}(0,0,1)$
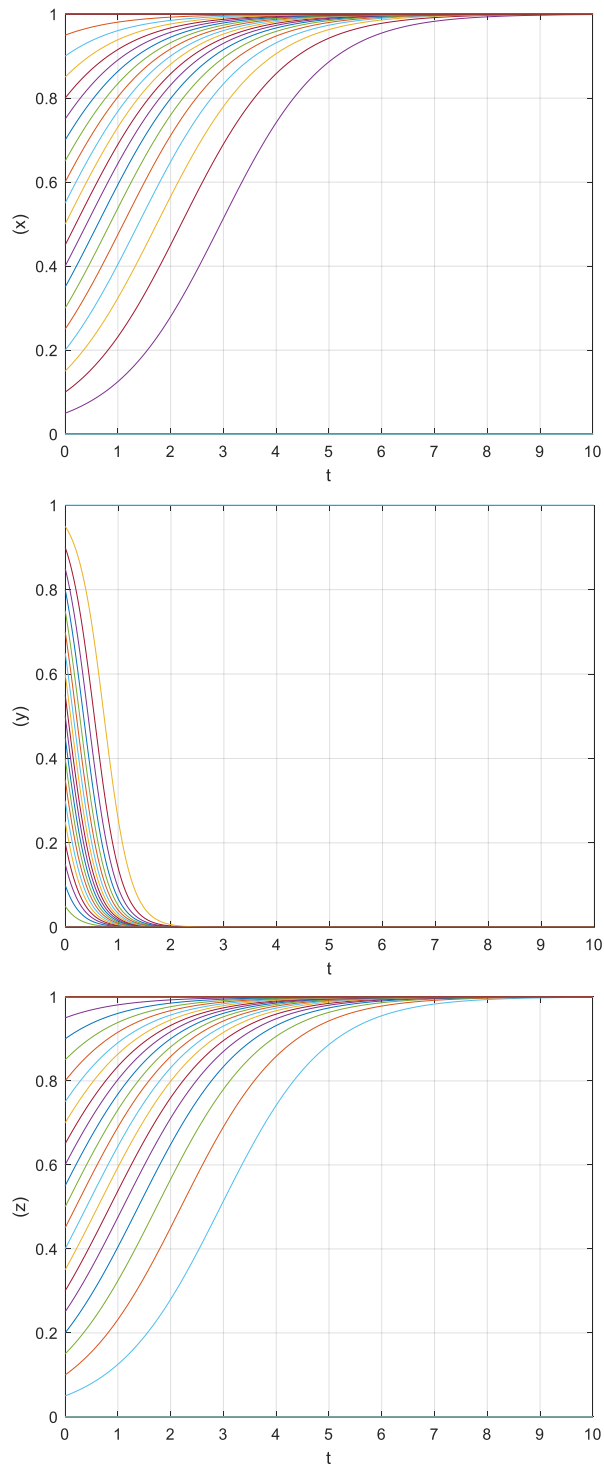

Fig.4 The evolution towards $E_{6}(1,0,1)$

As can be deduced from the fig.4, the probability $x, y, z$ will eventually converge to $E_{6}(1,0,1)$ regardless of the initial value. The greater the initial regulatory willingness of the central government, the faster it tends to regulate. When the initial intention is lack, if it can obtain positive benefits in the long term, it will eventually choose to regulate. However, local governments have the fastest convergence rate without policy incentives, so they will definitely choose the strategy with less loss, that is, no incentives, when the benefits are always negative. When the initial intention of the enterprise is low, the time period for the final selection of positive response strategy is long. The higher the initial intention is, the faster the selection of positive response will be. Therefore, when the regulatory cost of the central is less than the benefits obtained, the total return of the central state is positive, so the central state has an incentive to supervise the local government. For local governments, even if the central supervision, they will not give policy incentives when their own policy implementation costs and subsidies to enterprises are rather large. The positive response of enterprises to the policy brings more benefits than the previous benefits, so enterprises have the incentive to participate in the green finance policies, but the development of green innovation by relying on their own strength is very slow, so the central and local policy support is very 
necessary for enterprises to accelerate green development.

\section{(5)Scenario 5}

When the sum of the central government's regulatory costs and subsidies to local governments is less than the difference in social benefits between the central government's choices of regulation and non-regulation $\left(b+s_{1}<v_{1}-v_{2}\right)$, the sum of the subsidies from the central government and the fines for no policy incentives is greater than the sum of the implementing costs and the financial subsidies to enterprises $\left(s_{1}+d>s_{2}+m\right)$, the difference between the benefits and costs of enterprises' positive response, plus the subsidies given by local governments, is greater than the difference between the benefits and costs of negative response $\left(s_{2}+e_{1}-c_{1}>e_{0}-c_{0}\right.$ ), the central state would take the regulatory measures, the local provinces would provide the incentive polices, and the enterprises would positively response the governments in this case. Thus, we supposed that $d=4, b=2, m=3, s_{1}=3, s_{2}=3, v_{1}=10, v_{2}=3, c_{0}=2, c_{1}=3, e_{0}=5$, $e_{1}=4$. Numerical simulation results satisfying the above constraints are shown in fig.5.
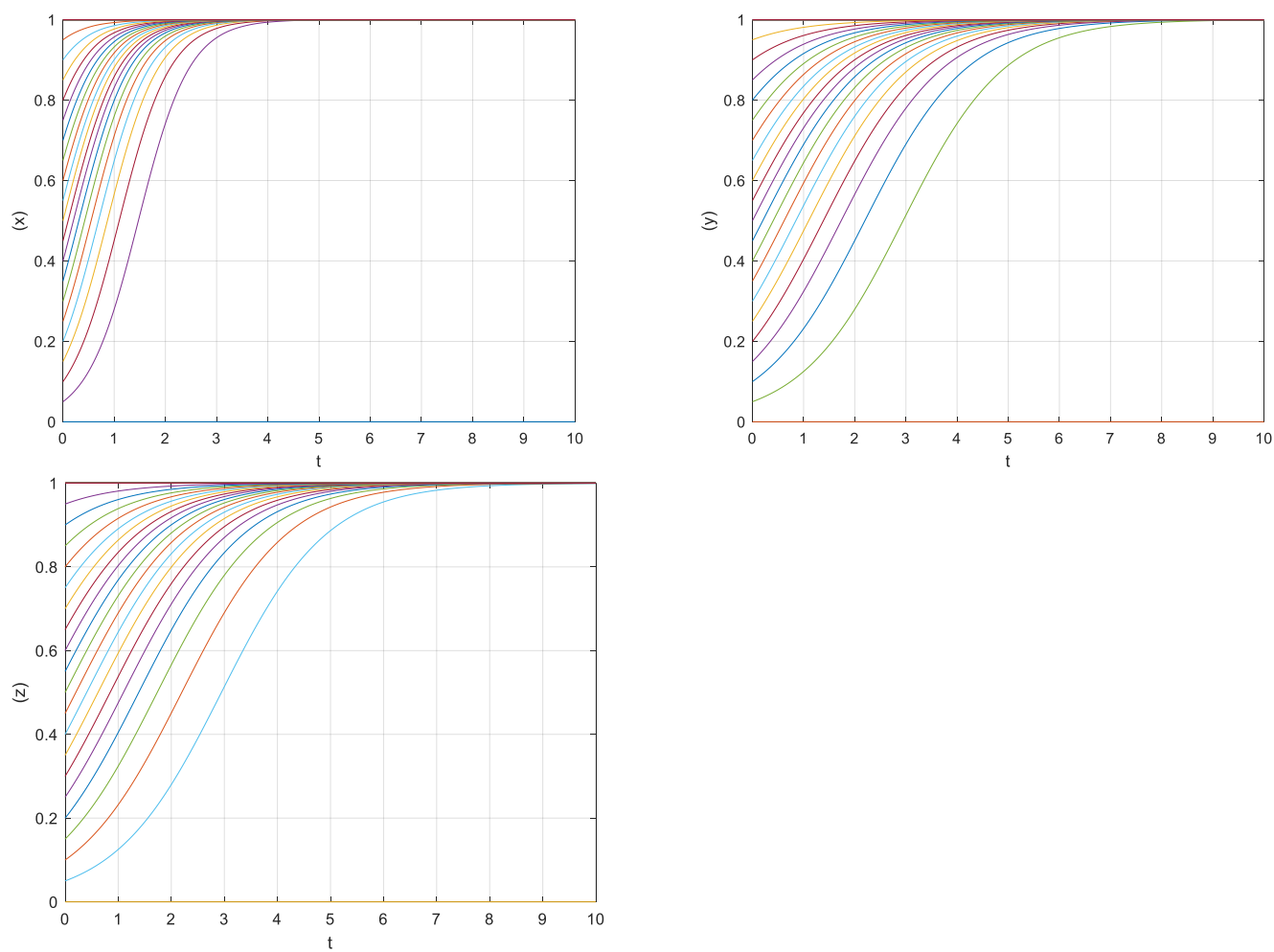

Fig.5 The evolution towards $E_{8}(1,1,1)$

As can be seen from the fig.5, the probability $x, y, z$ will continue to increase over time until 1, no matter what the initial value is. Only if these conditions are met, the final ESS must be $E_{8}(1,1,1)$. The convergence rate of central government regulation is the fastest, because the social benefits brought by regulation are relatively large. Even if the initial intention is low, it can be converged to 1 in a short time. The intention of central government regulation is relatively strong. The higher the initial probability of local provinces and industrial companies to choose the strategy, the faster the speed tends to 1 . In this case, the choice of policy incentives and positive responses can maximize their own interests. Therefore, when the regulatory cost paid by the central state and the subsidy given to local states, namely the total cost of the central is less than the total benefit, the central state will choose to regulate. Under the central management, if the financial subsidies and policy implementation costs of local provinces for industrial companies are relatively small, local provinces will have greater willingness to ISSN: 0010-8189 
provide policy incentives. Under the dual incentives of central supervision and local subsidies, when the benefits brought by enterprises' positive response to the policy and the subsidies are larger than the previous benefits, in the future, it is helpful for enterprises to develop, and enterprises would be more active in green finance policies.

\subsection{Analysis of the influence of main variables on the strategy selection of the game partner}

The above analysis proves that different values of variables will affect their decisions, the central, local provinces and industrial companies. Therefore, we will assign different values to the main variables. The initial value of the regulatory willingness of the central state, the incentive willingness of local provinces and the policy participation willingness of enterprises is set as $x, y, z \in(0.5,0.5,0.5)$. Then it analyzes the influence of the change of the five major variables on the will of the three parties: the policy subsidy of the central state, the subsidy of the local provinces to industrial companies, the supervision cost of the central state, the punishment of the local provinces and the cost of green innovation of industrial companies. In order to facilitate the research, if the other variables are not changed, the initial values of the above mentioned research variables are respectively set as low, medium and high levels, and MATLAB R2018a software is used for simulation.

(1) The effect of the central subsidies on the evolution results

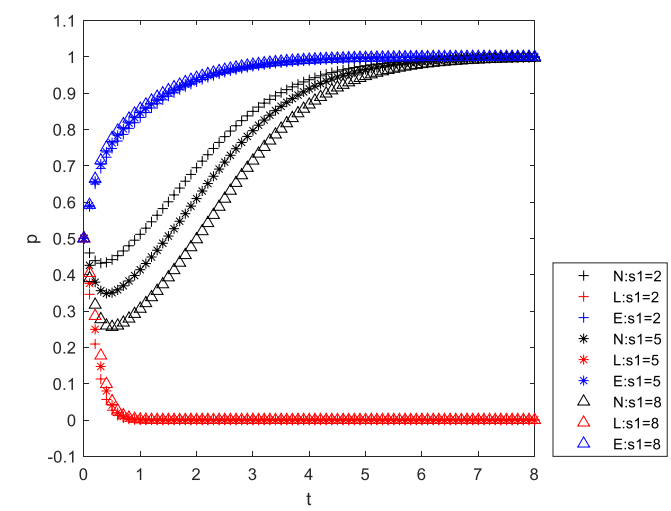

(a) Scenario 4

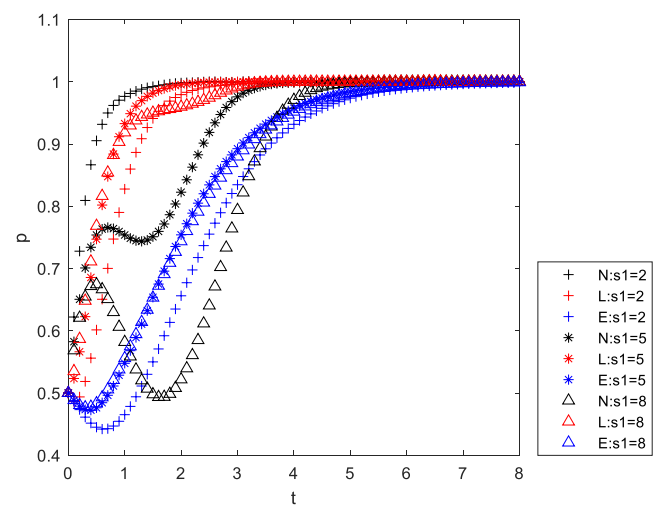

(b) Scenario 5

Fig. 6 Evolution of central subsidies to local governments

In order to analyze the influence of policy subsidy $s_{1}$ from the central to the local provinces on the decision-making of stakeholders, scenarios 4 and 5 above are selected for simulation. When other variables are fixed a certain extent, the value of $s_{1}$ is reset to 2,5 and 8 levels for simulation, and the results are seen in fig.6. As can be seen from fig.6(a), with the increasing of the central subsidy intensity $s_{1}$, the speed of the central regulate willingness tends to 1 gradually decreases. The policy incentive intention of local provinces tends to zero and the speed slows down. And the positive response of enterprises to the green finance policies has been improved to some extent. In fig.6 (b), these changes are more obvious. When $s_{1}$ is equal to 2 , the central regulatory intention approaches 1 at the fastest speed. When $s_{1}$ continues to increase, there is a temporary downward trend. The greater the value of $s_{1}$ is, the more obvious the downward trend will be. However, with the increasing willingness of local provinces and enterprises to participate, the willingness of the central to regulate will also increase. The bigger the subsidy from the central, the faster the willingness of local governments and enterprises to participate tends to 1 . This suggests that incentives from the central government can facilitate local government policy implementation. In fact, the relationship between the central and local states is the key to the implementation of policies. And reasonable incentives can improve the execution of local environmental policies. In addition, the policy subsidies of the central government also have a positive effect on enterprises' green innovation. This is because the central subsidies can reduce the policy costs of local governments, and local provinces have more incentive to give policy incentives to enterprises, so as to encourage enterprises to actively participate in green finance activities. It is worth noting that when the subsidies of the central government are too 
high, it will also impose a certain burden on the central state, thus reducing the willingness of the central province to regulate.

(2) The influence of subsidies provided by local provinces on the evolution results

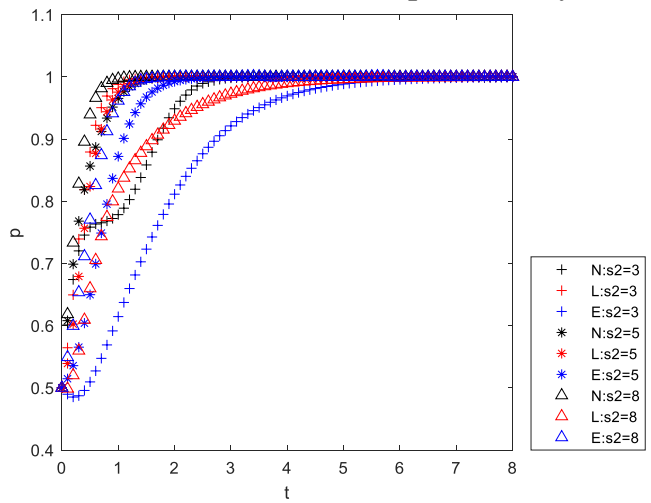

Fig.7 Local government subsidies to enterprises

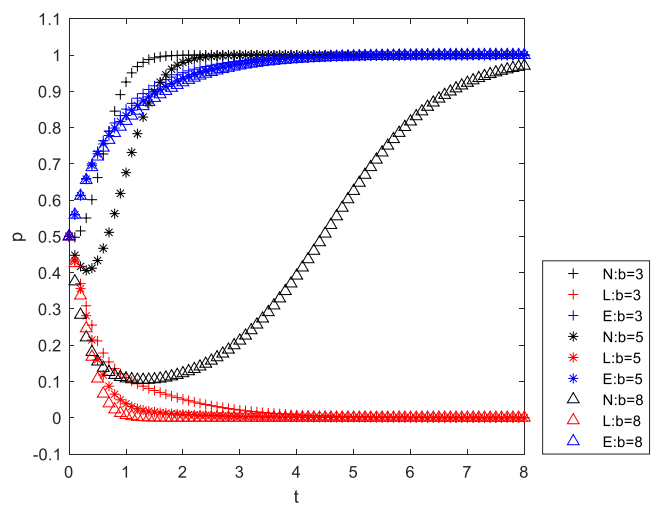

Fig.8 Central government supervision costs

Local governments give certain subsidies to enterprises that actively respond to policies, namely $S_{2}$, which will also affect the decision-making of stakeholders. Scenario 5 in the preceding paper is selected for simulation. If other parameters remain unchanged, $s_{2}$ values are reset to 3, 5 and 8 for next simulation, the results are listed in fig.7. Based on fig.7, with the increase of local government subsidy $s_{2}$ to enterprises, the speed of local government policy incentive intention tending to 1 is slower, and the faster the central government's regulatory appetite tends to 1 . When $s_{2}$ is relatively low, the regulatory willingness of the central government is also relatively low, showing a relatively flat segment in the figure. With the strengthening of the participation willingness of local provinces and enterprises, the regulatory willingness of the central government is gradually tending to 1 . For enterprises, when local government subsidies are less, the willingness of enterprises to participate in the short term has shown a downward trend. As subsidies increase, the downward trend disappears. The bigger the subsidy, the faster the willingness to participate tends to 1 . This result shows that local government subsidies to enterprises will affect the central government's willingness to regulate and enterprises' willingness to participate, and local government subsidies can promote enterprises to actively participate in green finance activities. This is because local government subsidies can strengthen the environmental responsibility of enterprises, reduce the innovation cost, and improve enterprise to make innovations. Peng ${ }^{[9]}$ also proved that development of enterprises could enjoin the great benefit of government subsidies.

(3) The influence of the regulatory cost on the evolution results

The central state supervises local provinces, and the regulatory cost $b$ will affect the decisions of stakeholders.

Scenario 4 is selected for simulation in the last paper. When other parameters aren't changed, the values of $b$ are reset to 3, 5 and 8 for simulation, the simulation outcomes is demonstrated by fig.8. As could be deduced that with the increase of regulatory cost $b$, the regulatory willingness of the central government tends to 1 at a slower and slower speed. At $b$ equals 5, there is a brief downward trend in the regulatory will of the central government. When the regulatory cost continues to increase to 8 , the downward trend becomes more obvious, and the regulatory curve of the central government becomes very smooth, and the speed towards 1 is the slowest. As the cost of central regulation rises, the willingness of local governments not to offer policy incentives to firms is going to zero faster. This result shows that the regulatory cost of the central state greatly influences the regulatory the central decision, and reducing the regulatory cost could better the regulation initiative of the central state. If the cost of regulation is high, the central government may abandon it for its own sake. The cost of supervision will also aggravate the information asymmetry among the central state, local provinces and companies, thus affecting the implementation effect of policies. Therefore, for effectively implement the green finance policies, it is essential for 
the central state to reduce the regulation cost and improve the regulatory willingness.

(4) The impact of the central fine on the evolution results
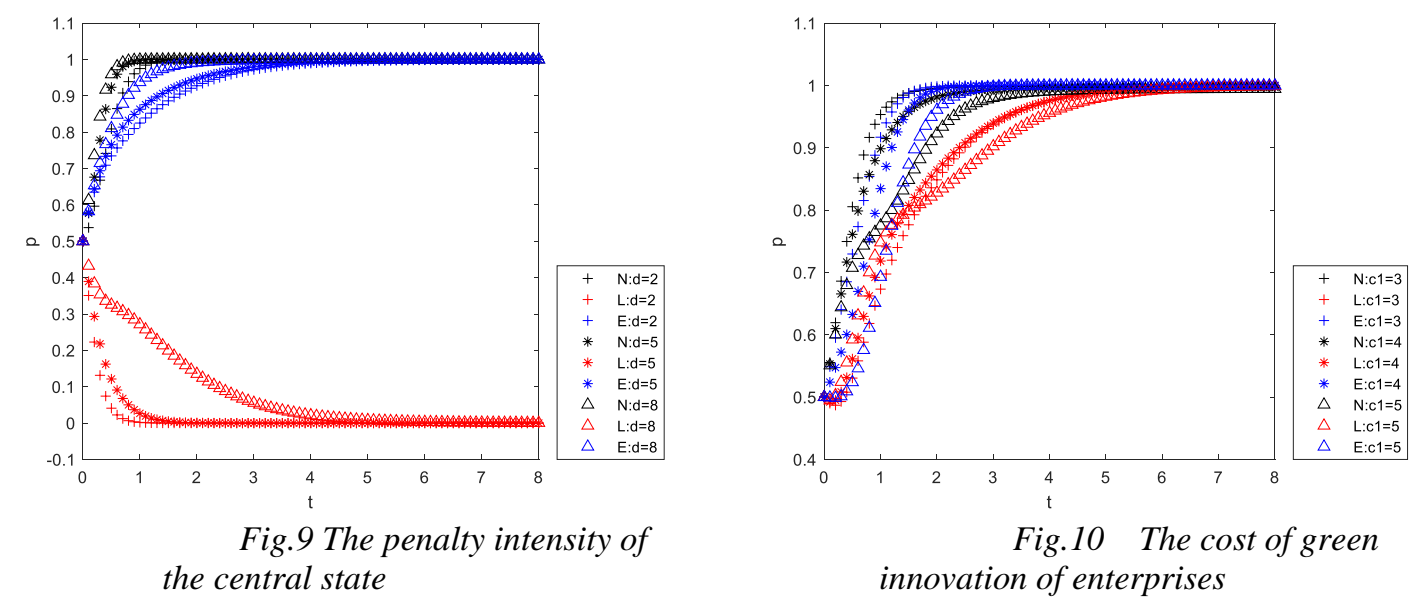

The central government supervises local governments. If it is found that local state takes no corresponding green finance measures, the size of penalty $d$ on local governments would produce an effect on the stakeholder's action. Scenario 4 is selected for simulation. When other parameters remain unchanged, $d$ values are reset to 2,5 and 8 for simulation, the result is illustrated in fig.9. As could be got from the fig.9, the larger the fine $d$, the faster the regulatory willingness of the central government and the willingness of enterprises to participate tend to 1. However, when the central fine is relatively low, the local policy incentive intention tends to 0 at a relatively fast speed. When the central fine is increased to 8 , it will greatly slow down the speed of the local government's policy incentive intention tends to 0 . The simulation outcomes show that the central fine can enhance the regulation from the central state. Fines imposed by the central state can also boost the willingness of local governments to provide policy incentives. Under the background of high penalties, if the local government does not implement the policy, they will have to pay expensive financial fine. In contrast, the local government should give policy incentives to enterprises in order to maximize their own interests. Therefore, strengthening the supervision of the central government is helpful for the implementation of green finance policy. Similarly, Zhang ${ }^{[10]}$ found that the supervision of the central government has a certain positive effect on the implementation of policies by local governments. The main reason is that the direct supervision of the central government can effectively reduce the information asymmetry between the central and local governments and improve the implementation efficiency of policies. As an important part of China's policy implementation, the central government's supervision can not only regulate the behavior of local governments, but also enhance the willingness of enterprises to respond positively to policies and effectively promote the green transformation of enterprises.

(5) The impact of company's green innovation costs on the evolution results

Companies actively respond to green financial policies while green production and green innovation are all at the costs, defined as $c_{1}$, which would disturb stakeholders to make their decisions. Therefore, scenario 5 above is selected in this paper for further simulation analysis. When other parameters are not unchanged, the value of $c_{1}$ is reset to 3, 4 and 5 respectively, the simulation results are seen in fig.10. According to fig.10, with the increase of green innovation cost $c_{1}$, the regulatory willingness of the central state, the incentive willingness of local provinces and the response willingness of companies all slow down to 1 . If green innovation needs the more cost, the willingness of enterprises participating in policy has a temporary downward trend. But with the increase of the willingness of central supervision and the incentives willingness of local governments, enterprises will eventually choose the positive response strategy. The simulation results show that the cost of green innovation will affect the decision-making of enterprises in response to the green finance policies. After all the main goal of enterprise is to maximize its benefits, when the green cost is high so that the profit of enterprise decreases. However, if the central

ISSN: 0010-8189 
government and local government give some supports to the enterprise, the participation willing of enterprise can be promoted greatly. As is well proved that government subsidy could obviously help companies to do innovation activities. Therefore, the central state and local provinces should actively guide company to develop innovation activities in the sustainable field and promote the implementation of finance policies of green development.

\section{Conclusions and suggestions}

\subsection{Conclusions}

Because the implementation of green finance policies is a process of multi-partner coordination, this paper establishes a dynamic evolutionary game model of the central state, local province and company, studies the behavior strategies of three partners in the implementation of green finance policies by solving the game equilibrium points, and simulates numerically the process of ESS. The conclusions are as follows:

(1) The positive response willingness of enterprises to finance policies of green development is related to the costs and benefits which they win in green innovation. To some extent, the policy incentives of local governments can also enhance the positiveness of companies to participate in the policies. Direct supervision by the central state could significantly better information asymmetry between the central state and local provinces and improve the compliance of industrial company to participate the finance policies. The greater the regulation and the more preferential policies are given, the more guaranteed the enterprises' green finance activities will be, the stronger their willingness to participate.

(2) Local governments are responsible for the prosperous of sustainable finance, and they consider the main factors are law enforcement costs and green subsidies to industrial companies. When implementing cost is very expensive which means damage the interests of local governments, so that the willingness of providing policy incentives will be greatly reduced. The supervision and punishment measures of the central state can regulate the execution behavior of local provinces and promote the game to go to the ideal stable state.

(3) Due to the inconsistent interests among different partners, the implementation of green finance policies by local provinces is far from what the central state expects in the beginning of policy design. Therefore, it is essential for the central state to keeps good discipline in the process of implementation and management, that is to say, the policy supervision of the central government is a strong guarantee for the boom of sustainable finance. While the supervision cost and punishment intensity are key variables which affect the central government supervises or not. To a certain extent, the social benefits and cost will also affect decision making of the central state, so decreasing the management cost and increasing the deterrent force of fines could effectively improve the social effect of green finance policies.

\subsection{Suggestions}

Focusing on every partner in the implementation practice of green finance, the research proposes the following suggestions:

(1) The central government, as a policy maker, should not only design perfect green finance policies, but also supervise the implementation of local governments and regulate their implementation behaviors, so as to make sure the smooth implementation of sustainable finance policies and promote harmonious relationship between economy development and environment protection. Firstly, the central government should enhance the authority and binding force of green finance policies from the legal level and improve the complete legal framework of sustainable finance for green development. Secondly, the essence of green finance is still commercial and market-oriented, therefore, it is necessary to provide priority to market mechanism in the decision of resource allocation, guide resources to be invested in the green fields of energy utilization and environmental governance through the construction of market mechanism, promote the green development and adjusting of industrial structure, and make sustainable finance better serve the real economy. Finally, the central government should continuously establish ISSN: 0010-8189 
and perfect the decision feedback correction mechanism and decision-making responsibility system, so as to create a good green financial market atmosphere and guide enterprises to participate in more actively.

(2) The development of green finance has a certain positive externality, so local governments should play an important role in the market-oriented improvement of green finance policies, standardization of enterprise behaviors and active participation of enterprises. As the concrete executor of policies, local governments should not only face the supervision of the central government, but also provide policy incentives to enterprises on the basis of guaranteeing their own interests. First of all, local governments should formulate the detailed policy implementation plans with local social characteristics and constantly improve China's green finance policy system. Secondly, within their own financial resources, local governments should formulate reasonable policy incentive schemes, including financial subsidies, tax incentives, risk compensation and credit guarantee and so on, for the sake of reducing the financing cost of industrial enterprises' sustainable projects and improve the risk tolerance of investors. Positive incentives should not only benefit enterprises, but also fully mobilize the enthusiasm of financial departments, reduce the threshold requirements of green financial business, and encourage financial institutions to develop diversified green financial services. Finally, the local government should also make complete punish measures for enterprises breaking out the law, improve the systems for monitoring and evaluating environmental protection and for determining accountability for environmental problems, so as to ensure the efficient and orderly implementation of policies.

(3) The fundamental goal of green finance is to promote the green innovation and sustain of industrial enterprises, only rely on government subsidies and incentives, enterprises are very difficult to achieve sustainable development. Therefore, enterprises should first establish the concept of green development, enhance the awareness of sustainable development to improve the energy efficiency and decrease environmental pollution, and take the initiative to fulfill social responsibility. Secondly, enterprises should improve their environmental information disclosure system, timely report normative information to the public, and set an example of good reputation, in order to reduce information asymmetry, regulatory costs and penalty risks. Finally, enterprises should continue to pursue excellence in talent construction, system innovation, product research and development, technological change and other aspects, and fundamentally achieve high quality development.

\section{Acknowledgments}

The research is supported by National Social Science Fund of China (19BJY086), Social Science Planning Project of Fujian Province (FJ2020B112), Educational Research Project of Young and Middle-aged Teachers in Fujian Province (Social Science, JAS20151), Jimei University Scientific Research Startup Project (Q202107).

\section{References}

[1] H. Song, C.G. Zhao, J.P. Zeng, "Can environmental management improve financial performance: An empirical study of a-shares listed companies in China”, Journal of Cleaner Production, vol. 14, pp. 1051-1056, 2017.

[2] Y. Wang, Q. Zhi, “The Role of green finance in environmental protection: two aspects of market mechanism and policies", Energy Procedia, vol. 104, pp. 311-316, 2016.

[3] J. Sheng, W. Zhou, B. Zhu, "The coordination of stakeholder interests in environmental regulation: lessons from China's environmental regulation policies from the perspective of the evolutionary game theory", Journal of Cleaner Production, vol. 249, no.119385, 2020.

[4] M. Alastair, "Transforming climate finance and green investment with block chains", Academic Press, 271-272, 2018.

[5] X.L. Jiang, Q.B. Zhang, "Overview of green finance theory and practice in developed countries", China Population, Resources and Environment, vol. 27, no.S1, pp. 323-326, 2017. (in Chinese)

[6] L.Y. He, R.Y. Liu, Z. Zhong, et al., "Can green financial development promote renewable energy investment efficiency? A consideration of bank credit", Renewable Energy, vol. 143, pp. 974-984, 2019. 
[7] B. Zhang, Y. Yang, J. Bi, "Tracking the implementation of green credit policy in China: Top-down perspective and bottom-up reform", Journal of Environmental Management, vol. 92, no.4, pp. 1321-1327, 2011.

[8] J.Y. Liu, Y. Xia, Y. Fan, et al., "Assessment of a green credit policy aimed at energy-intensive industries in China based on a financial CGE model”, Journal of Cleaner Production, vol.163, pp. 293-302, 2017.

[9] H.T. Peng, Y. Liu, "How government subsidies promote the growth of entrepreneurial companies in clean energy industry: an empirical study in China”, Journal of Cleaner Production, vol. 188, pp. 508-520, 2018.

[10] B. Zhang, X.L. Chen, H.X. Guo, "Does central supervision enhance local environmental enforcement? quasi-experimental evidence from China”, Journal of Public Economics, vol. 164, pp. 70-90, 2018. 